\title{
An Investigation on Corrosion Behavior of a Multi-layer Modified Aluminum Brazing Sheet
}

\author{
Wei LIU ${ }^{1, \mathrm{a}}$, Zhenming YANG ${ }^{1, \mathrm{~b}}$, Long $\mathrm{LI}^{1, \mathrm{c}}$, Dejing ZHOU ${ }^{1, \mathrm{~d}}$ \\ ${ }^{1}$ Yin Bang Clad Material Co., Ltd., Wuxi Jiangsu, China \\ awei.liu@cn-yinbang.com, bhenming.Yang@cn-yinbang.com \\ 'long.li@cn-yinbang.com, ddejing.zhou@cn-yinbang.com
}

\begin{abstract}
The corrosion behavior of a multi-layer modified aluminum brazing sheet (AA4045/3003Mod./AA7072/AA4045) was investigated. The results shows that, the existence of BDP, which forms at the interface between clad and core layer during brazing, changes the corrosion form of the air side of the material from inter-granular corrosion to local exfoliation corrosion. The addition of anti-corrosion layer makes the corrosion form of the water side from inter-granular corrosion into uniform exfoliation corrosion. Compared to the normal triple-layer brazing sheet at the same thickness, the time to perforation of the modified four-layer brazing sheet is increased by more than $200 \%$.
\end{abstract}

Key words: aluminum alloy; brazing sheet; corrosion behavior

\section{Introduction}

Aluminum alloys are of interest for various applications, particularly due to their high strength/weight ratio, good formability and good corrosion resistance in vehicles, household items, infrastructures, constructions, aerospace, etc. It has been calculated that for each kilogram of weight saved in a vehicle, a saving of $20 \mathrm{Kg}$ of $\mathrm{CO}_{2}$ emissions can be achieved. Therefore the use of aluminum in the automotive industry in order to produce more fuel-efficient vehicles and to reduce the energy consumption and air pollutions has increased greatly over the last few decades, from $20 \mathrm{Kg}$ in 1960 to a predicted level of more than $160 \mathrm{Kg}$ per vehicle in 2010 and 250 to $340 \mathrm{Kg}$ by 2015[1]. One of the increasing applications of $\mathrm{Al}$ alloys in vehicles is in heat exchangers (with tube and fin components) such as radiators, evaporators, engine cooling and air conditioning systems. Corrosion behavior of the brazed sheet is critically important since this is the major failure mode for automotive heat exchangers, especially under the trend of lightweight of automotive parts. By using the test methods of copper accelerated salt spray (CASS), acetic acid salt spray (AASS), sea water acid accelerated test (SWAAT) and the analysis techniques of optical microscopy (OM), scanning electronic microscopy (SEM), scanning Kelvin probe force microscopy (SKPFM), many studies have been done to characterize the corrosion behavior of the brazed AA4xxx/AA3xxx alloys. Initially, Scott et al.[2] and Isobe et al.[3] considered that noble Si needles acted as active cathodes thus make the surrounding aluminum dissolved. While a subsequent study[4,5] shown that Si particles do not have a detrimental effect on the corrosion behavior of the brazing sheets. And it is coincident with the study of Tohma et al.[6,7] that the oxygen reduction current density on silicon is too low to anodically polarize 
aluminum. The study of Tierce et al.[8] considered that the micro-battery effect between $\alpha-\mathrm{Al}(\mathrm{Fe}, \mathrm{Mn}) \mathrm{Si}$ phase, which generates during the brazing process[9], and the Al matrix are responsible for the corrosion in acidic or neutral solutions. In order to protect the core material, a type of modified AA3xxx aluminum alloy, which a certain amount of $\mathrm{Cu}$ is added, is widely used in place of the normal AA3xxx. And a investigation of the modified AA3xxx aluminum brazed sheet shown that the diffusion of $\mathrm{Cu}$ element to the re-solidified clad material during brazing will reduce the cathodic protection towards the core material[10]. Besides, a band of dense precipitates (BDP)[11,12]is formed in the interface between the clad and core materials, as a consequence of the diffusion of $\mathrm{Si}$ and $\mathrm{Cu}$ elements during brazing. And it is said that the existence of BDP will affect the corrosion behavior of the brazed material[13], however, there is no definitive mechanism about the effect above.

However, the studies above are mainly focused on the triple-layer brazed aluminum alloys. The study on the four-layer brazing sheet which an anti-corrosion layer was added is rare. With respect to the $7 \mathrm{xxx}$ series aluminum alloy, exfoliation corrosion is the typical form in the acidic solutions. Therefore, it is an effective way to increase the corrosion life by the means of adding a 7072 layer between the clad and core materials. This study aims to investigate the corrosion behavior of a self-developed four-layer modified Aluminum brazing sheet, and to be the theories storage for the new material development.

\section{Experiment}

Materials. A4 size sheet $(600 \mu \mathrm{m}$ thick) was cut from a rolled modified AA3xxx (3003 Mod.) aluminum alloy

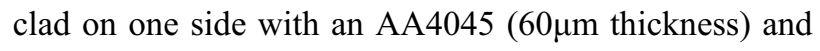

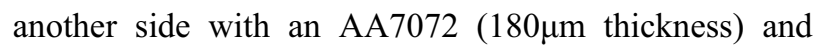
AA4045(60 $\mu \mathrm{m}$ thickness). The bulk chemical analysis of the clad, core and the anti-corrosion layer material is presented in Table 1.In order to distinguish easily during the test, two names are given to the each side of the material, namely, the air side (AA4045) and water side (AA4045+AA7072). All sheets used in these experiments before brazing were $\mathrm{O}$ temper.

The sheet was properly cleaned in ultrasonic bath with ethanol, dried and placed in a controlled atmosphere brazing $(\mathrm{CAB})$ furnace. $\mathrm{CAB}$ is brazing in a dry, inert nitrogen gas atmosphere. Brazing cycle that was applied is shown in Fig.1. The material is heated up to $605^{\circ} \mathrm{C}$ and is kept at that temperature for $3 \mathrm{~min}$. Then it is cooled down with a specified $\operatorname{ramp}\left(30^{\circ} \mathrm{C} / \mathrm{min}\right)$ in the furnace. And samples will be taken out and cooled in the air when the temperature is down to $390{ }^{\circ} \mathrm{C}$. The holding temperature was selected to be close to the liquidus temperature of the clad material, reported as $612^{\circ} \mathrm{C}$ by Lacaze et al.[14],while still being far below the solidus temperature of the core material which is about $640^{\circ} \mathrm{C}$.

Table1 Chemical composition (wt \%) of the core, anti-corrosion layer and clad material

\begin{tabular}{|c|c|c|c|c|c|c|}
\hline 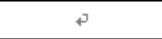 & $\mathrm{Si}$ & $\mathrm{Fe}^{\mathrm{T}}$ & $\mathrm{Cu}$ & $\mathrm{Mn}$ & $\mathrm{Mg}$ & $\mathrm{Zn}$ \\
\hline Clad(AA4045) & $10.0-11.0$ & 0.45 & 0.1 & $/$ & 0.02 & is \\
\hline Core $(3003 \mathrm{Mod})$ & 0.6 & 0.7 & $0.4-0.7$ & $1.0-1.5$ & 0.03 & 10 \\
\hline $\begin{array}{l}\text { Anti-corrosion } \\
\text { layer(AA7072) }\end{array}$ & \multicolumn{2}{|c|}{$\mathrm{Si}+\mathrm{Fe} \leq 0.7$} & 0.1 & 0.1 & 0.1 & $0.8-1.3+$ \\
\hline
\end{tabular}

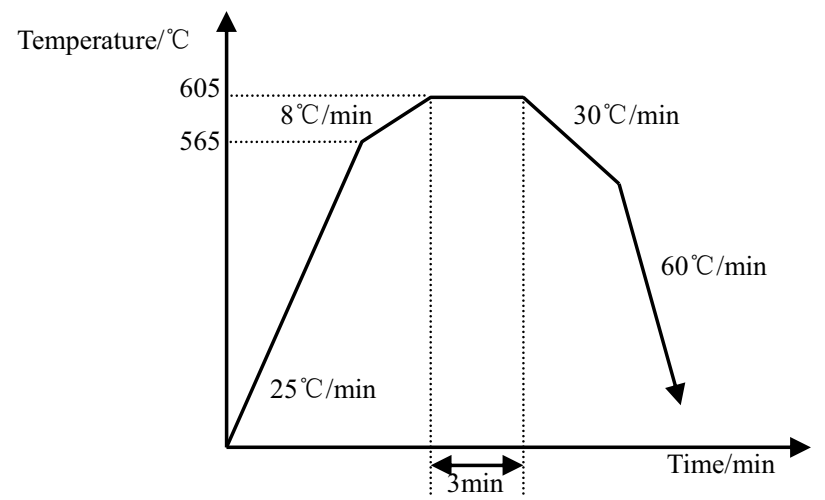

Fig.1 Standard controlled atmosphere brazing thermal cycle 
SWAAT procedure. Samples of $110 \mathrm{~mm} \times 60 \mathrm{~mm}$ were used. The back side was covered with $3 \mathrm{M}$ Scotch brand tape and the edges were protected with bee wax. In addition, another set of samples that cut from a normal triple-layer (AA4045/AA3003/AA4045) brazing sheet were prepared with the same brazing progress for SWAAT lifetime comparison. The samples were placed in the cabinet, tape side down, at an angle of $20^{\circ}$ and assessed every 7 days for corrosion attack mechanism and morphology of the cross section. The test comprises a repetitive two hours cycle consisting of $30 \mathrm{~min}$ spray followed by a 90 min soak at above $98 \%$ humidity[15]. The spray is a solution of $42 \mathrm{~g} / \mathrm{L}$ of sodium chloride and is acidified with $10 \mathrm{ml} / \mathrm{L}$ of glacial acetic acid. The $\mathrm{pH}$ is then adjusted with $10 \mathrm{wt} \% \mathrm{NaOH}$ solution to a value between 2.6 and 2.8. The temperature during spray and soak was kept constant at $49^{\circ} \mathrm{C}$.

Material characterization. Using ZEISS Imager.A2m Optical Microscopy (OM), Zeiss Sigma Scanning Electron Microscope (SEM) and Energy-Dispersive X-ray Spectroscopy (EDS), the microstructure of the material was examined both before and after brazing. For chemical characterization (elemental analysis) spectral imaging data sets (generated X-rays) were collected at 12 $\mathrm{kV}$. Image-Pro Plus was used to measure the size, number distribution density of particles in cross section. In order to make the concentration of the elements comparable, the same color scale has been applied for each element in different maps.

\section{Results}

Material characterization. Optical microstructures of the material under investigation both before and after brazing are shown in Fig.2. The image of the material before brazing shows the clad layer with a higher contrast. And the equiaxed or elongated coarse particles with a dark contrast in the clad layer are Si particles. The core material has a lower contrast, and some small particles exist with different chemical composition. For the anti-corrosion layer, it has the lowest contrast, and its approximate interface between the other layers is shown in Fig.2(a).

After brazing, as it is shown in Fig.2(b), Al-Si eutectic phase is accumulated at the surface of the residual clad and in between is the pre-eutectic aluminum grains. And a 30 40 $\mu$ m width diffusion zone is formed during the interaction between the liquid clad and the solid core material, which is called BDP (the band of dense precipitates), as it is shown in Fig.2(c).
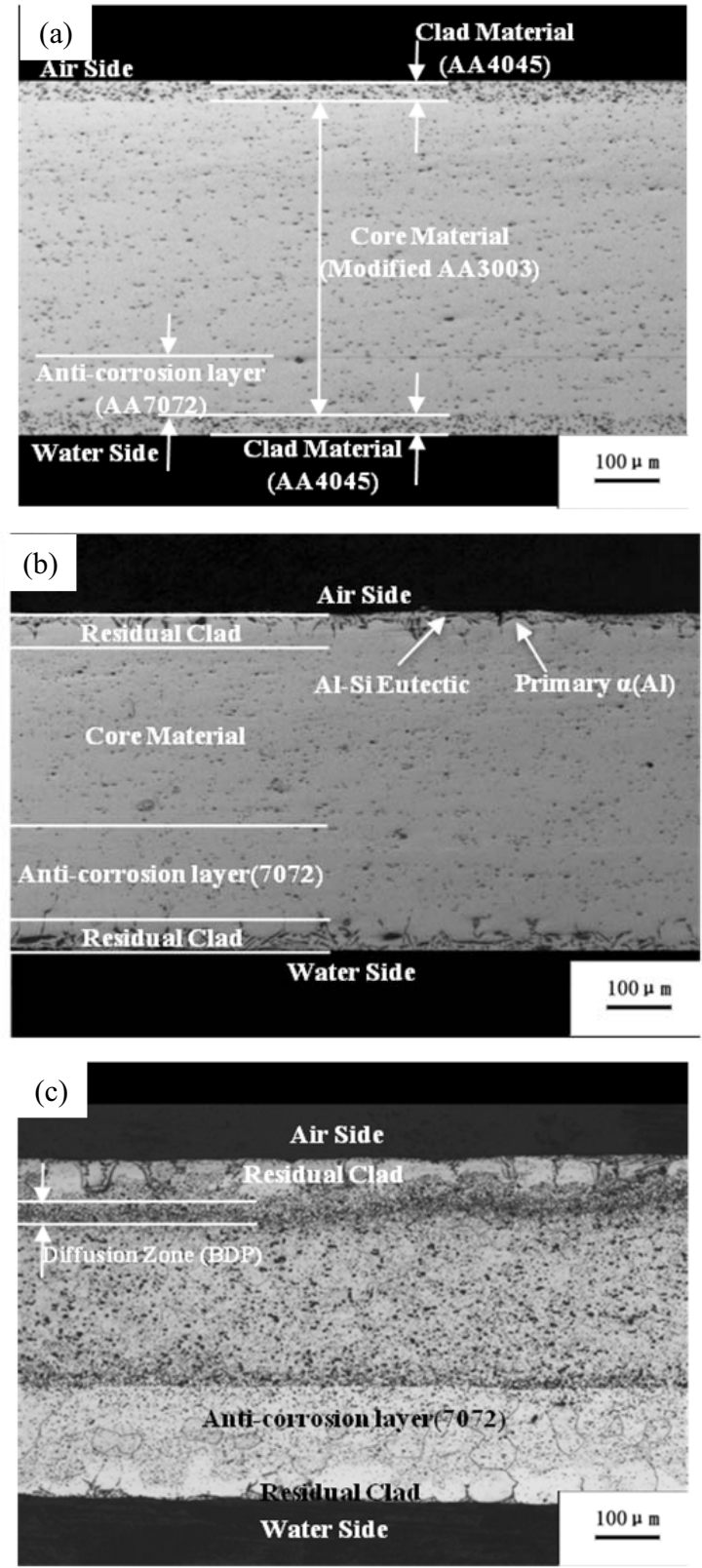

Fig.2 Optical microstructures of the brazing sheet: (a) before brazing; (b) after brazing; (c) after brazing (etched with keller reagent)

EDS map analysis for the major elements of the material under investigation both before and after brazing are shown in Fig.3 and 4, respectively. Comparison of the element maps in Fig.4 and Fgi.5 shows that it is the diffusion of $\mathrm{Si}$ and $\mathrm{Mn}$ elements during the brazing process that lead to the formation of BDP. 
A further EDS pitting analysis for the size and composition of the precipitates after brazing are shown in Fig.5 and table 2, respectively. As a result of resolution and diffusion, the residual clad material is comprised of three types of phases: $\alpha(\mathrm{Al})$, eutectic Si and $\alpha-\mathrm{Al}(\mathrm{Fe}, \mathrm{Mn}) \mathrm{Si}[11]$. For the diffusion zone, namely BDP, two types of particles are distinguished, regarding the size. One is the particles which are larger than $1 \sim 2 \mu \mathrm{m}$ (Spectrum5), and its size can reach up to $5 \sim 10 \mu \mathrm{m}$. The other type contains the particles (Spectrum4) with the size below $1 \mu \mathrm{m}$. And the result of Table 2 shows that the two types of particles are manly $\mathrm{Al}(\mathrm{Fe}, \mathrm{Mn}) \mathrm{Si}$ phases.

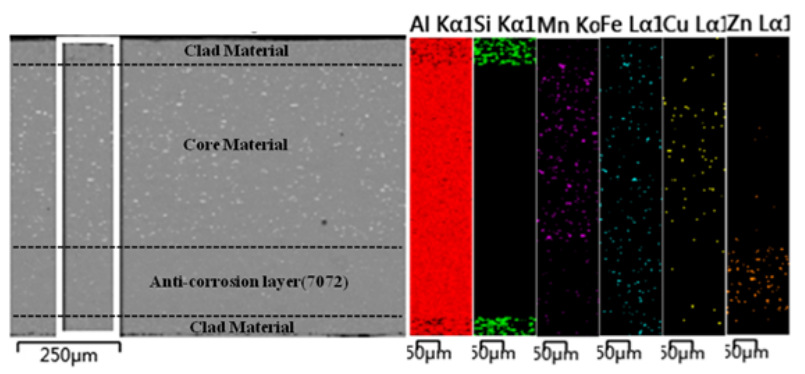

Fig.3 EDS element maps of the modified material before brazing

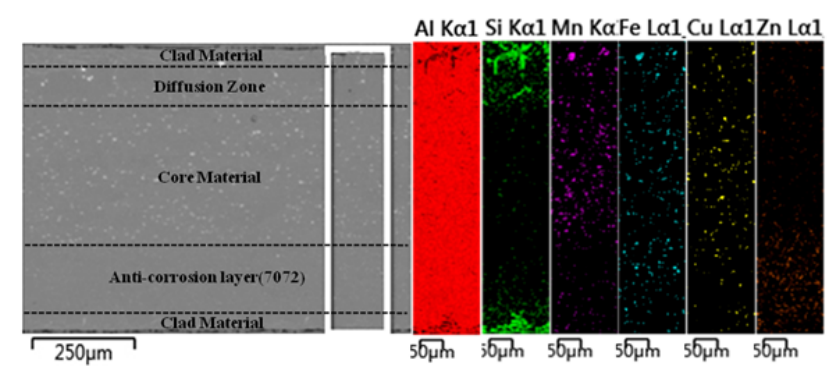

Fig.4 EDS element maps of the modified material after brazing

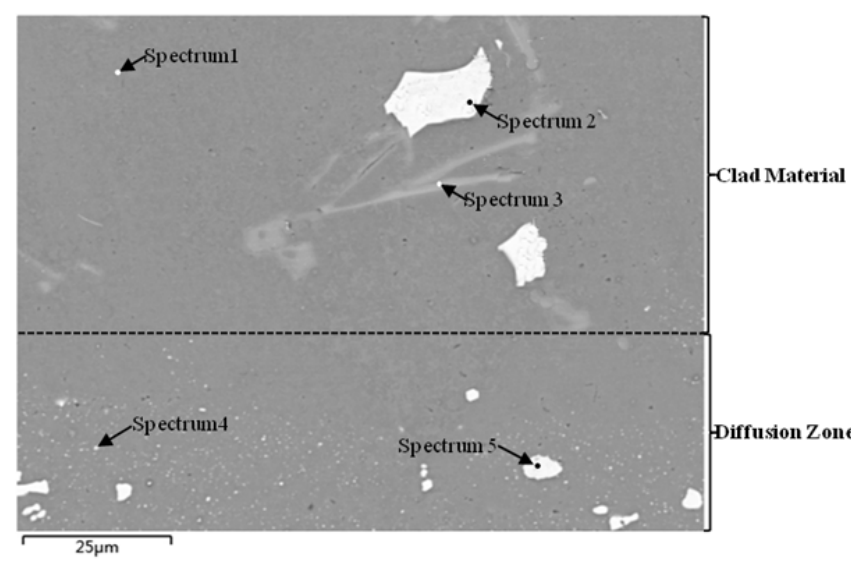

Fig.5 EDS pitting analysis of the modified material after brazing
Table 2 The composition of the precipitates after

\begin{tabular}{ccccccc}
\multicolumn{7}{c}{ brazing $(\mathrm{at} \%)$} \\
\hline Label & $\mathrm{Al}$ & $\mathrm{Si}$ & $\mathrm{Ti}$ & $\mathrm{Mn}$ & $\mathrm{Fe}$ & $\mathrm{Cu}$ \\
\hline Spectrum1 & 98.67 & 1.07 & 0.01 & 0.07 & 0.00 & 0.18 \\
Spectrum2 & 70.75 & 10.65 & 0.05 & 6.80 & 11.48 & 0.27 \\
Spectrum3 & 9.78 & 90.20 & 0.02 & 0.00 & 0.00 & 0.00 \\
Spectrum4 & 91.34 & 4.24 & 0.06 & 3.47 & 0.80 & 0.09 \\
Spectrum5 & 69.54 & 12.43 & 0.03 & 10.02 & 7.80 & 0.18 \\
\hline
\end{tabular}

The images managed by Image-Pro Plus shows the distribution of the precipitates in different areas away from the interface of modified the clad(AA4045) and core $(\mathrm{AA} 3003+\mathrm{Cu})$ materials are shown in Fig.6. And the statistical results are listed in Table 3 . As can be seen in table 3 , the number density of areas that $30 \sim 50 \mu \mathrm{m}$ away from the interface is much higher than areas that were not affected by element diffusion during brazing progress, which is good agreement with the BDP position identified in Fig.2(c).

Corrosion morphology characterization. The air side corrosion morphologies of the modified brazed material in different periods of SWAAT are shown in Fig.7. The corrosion begins in the eutectic $\mathrm{Al}$ at the surface in the form of pitting. Then it develops along the grain boundaries of the primary $\alpha(\mathrm{Al})$ to the diffusion zone, and the residual clad is partly exfoliation as a result of the corrosion of the diffusion zone, as it is shown in Fig.7(a) and (b). Finally, the material was failure in the form of IGC at the corrosion period of 28 days.

The water side corrosion morphologies of the brazed modified material in different corrosion periods are shown in Fig.8. As with the brazing side, the corrosion begins in the eutectic $\mathrm{Al}$ at the surface in the form of pitting. Then it develops along the grain boundaries of the primary $\alpha(\mathrm{Al})$ to the anti-corrosion layer (7072 layer), and the residual clad is uniformly exfoliation as a result of the corrosion of the 7072 layer, as it is shown in Fig.8 (a) and (b). Finally, the material was failure in the form of IGC at the corrosion period of 28 days. The result of the SWAAT shows that the time to perforation of the modified four-layer brazed sheet in the sea water solution is less than 28 days. 

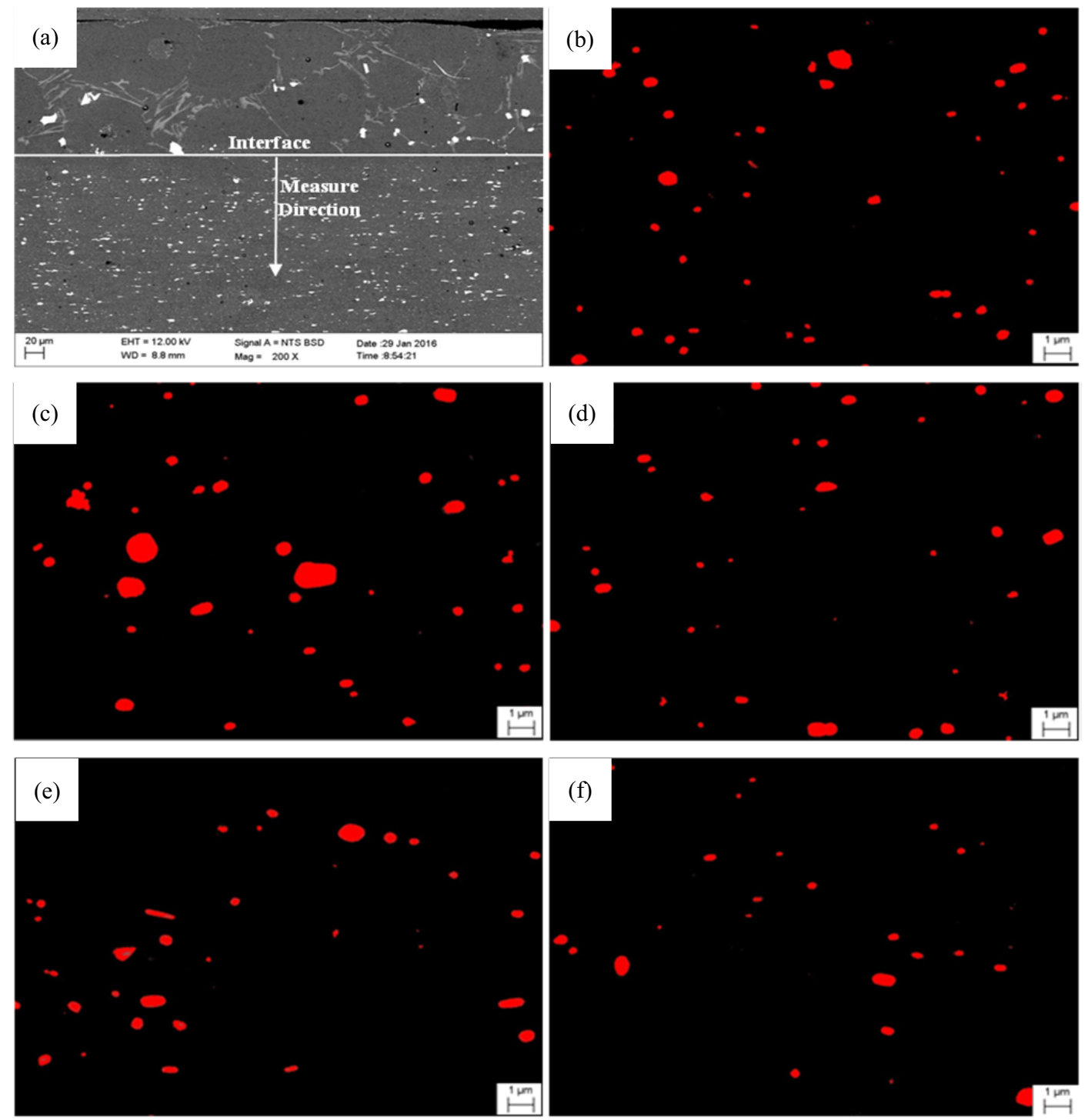

(f)

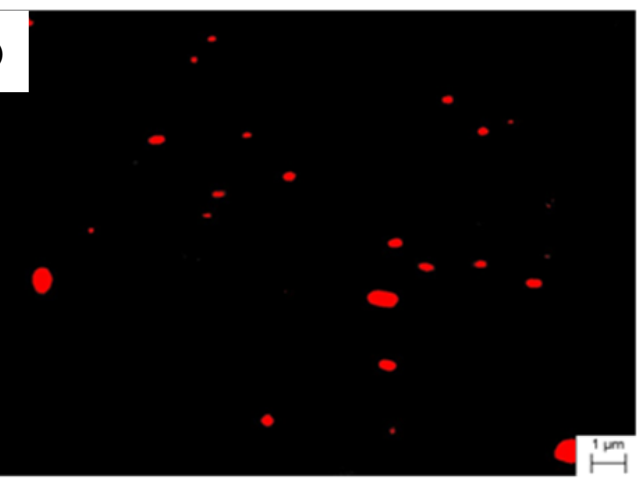

Fig.6 The distribution images of the precipitates in different areas away from the interface between the clad and core materials:

(a) the diagram of the observation; (b)30um; (c)50um; (d)70um; (e)90um; (f)110um

TABLE 3 STATISTICAL NUMBERS OF THE PRECIPITATES IN DIFFERENT AREAS AWAY FROM THE INTERFACE BETWEEN THE CLAD AND CORE MATERIALS

\begin{tabular}{cccc}
\hline & $\begin{array}{c}\text { Distance to } \\
\text { Interface }(\mathrm{um})\end{array}$ & Precipitate Number & $\begin{array}{c}\text { Number Density } \\
\left(\text { per um }{ }^{2}\right)\end{array}$ \\
\hline Diffusion & 30 & 53 & 0.604087 \\
Areas(BDP) & 50 & 48 & 0.547097 \\
Diffusion-free & 70 & 45 & 0.512904 \\
Areas & 90 & 36 & 0.410323 \\
\hline
\end{tabular}



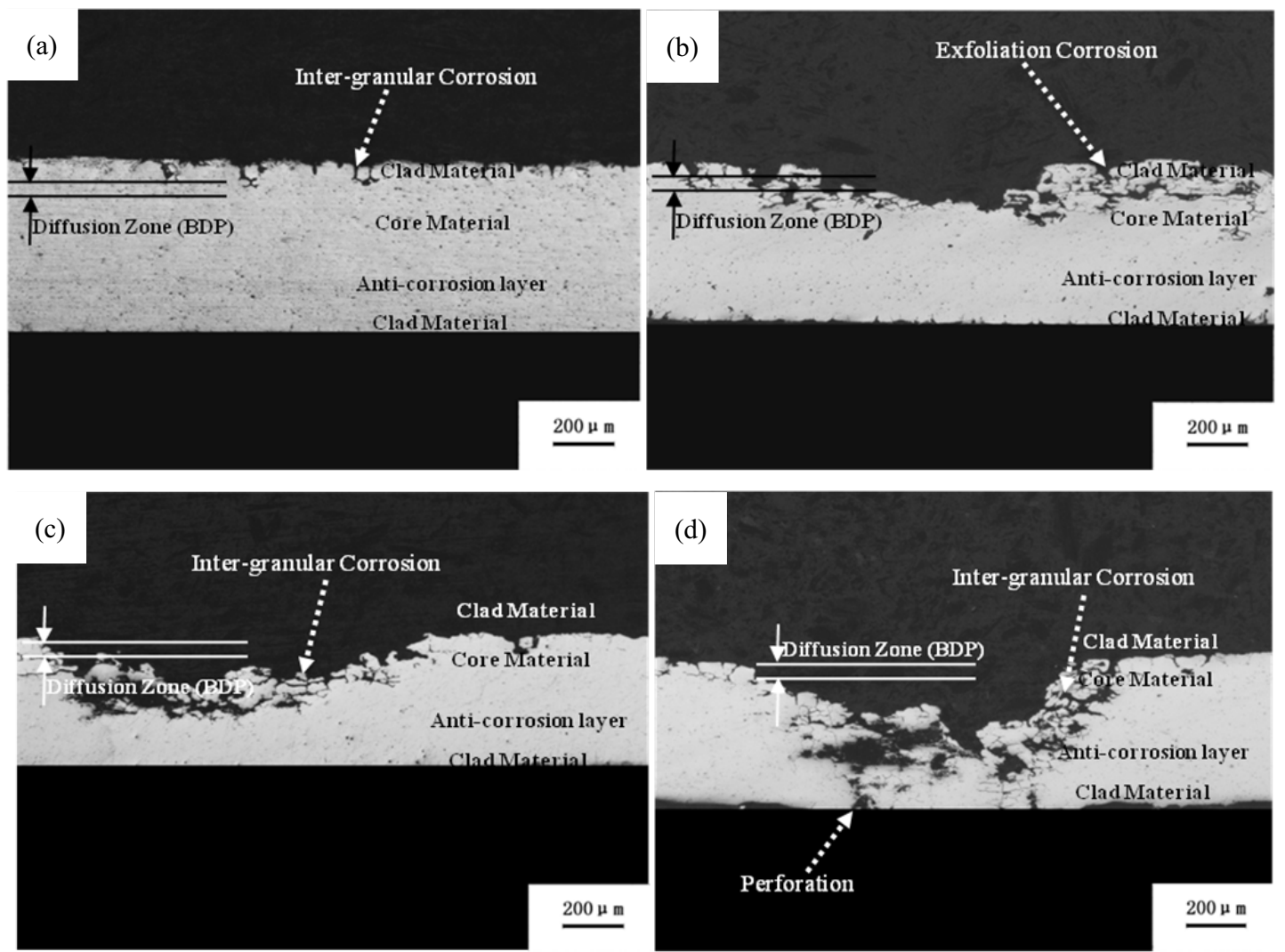

Fig.7 The air side corrosion morphologies of the modified material in different corrosion periods: (a)7d; (b)14d; (c) 21d; (d) $28 \mathrm{~d}$

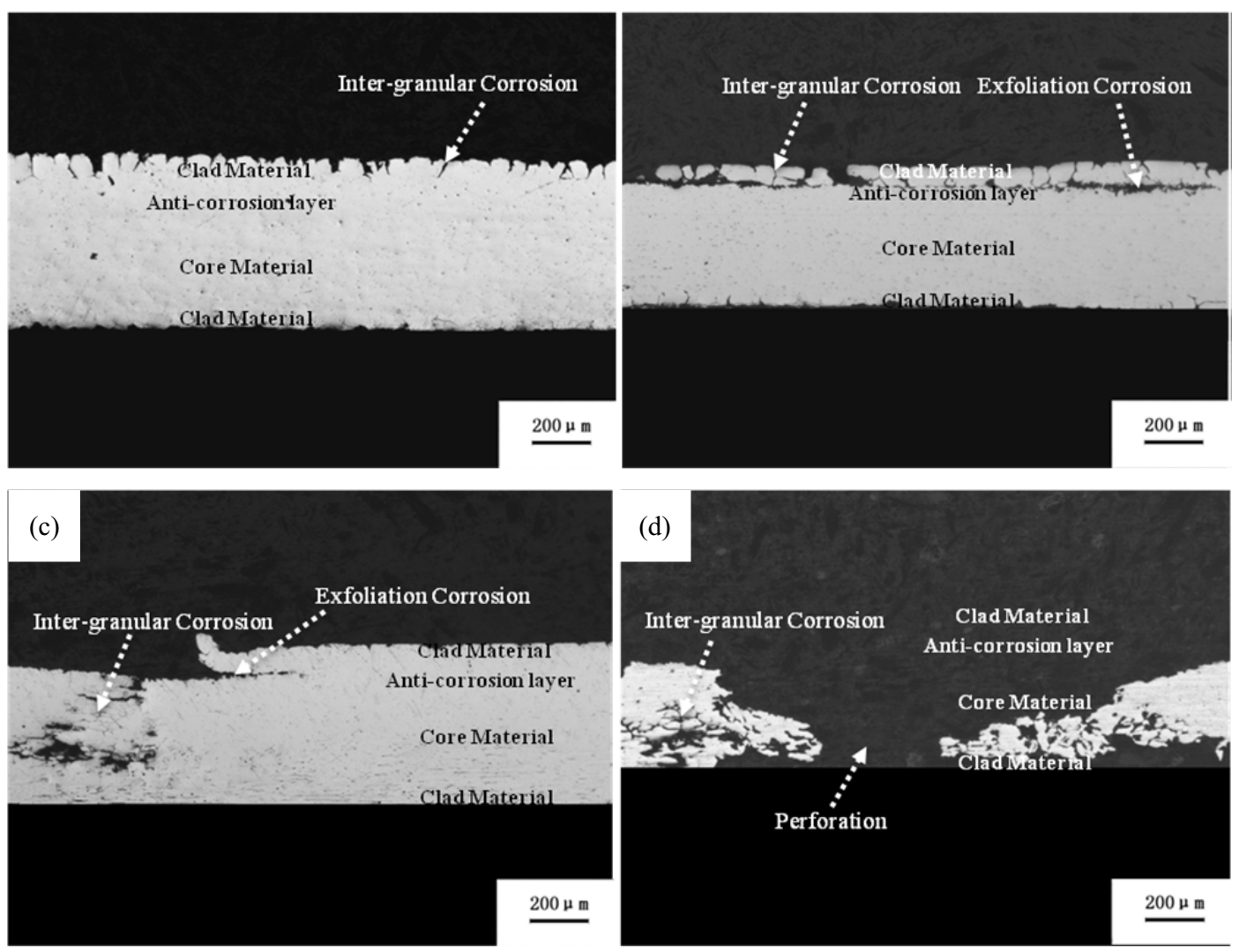

Fig.8 The water side corrosion morphologies of the brazed modified material in different corrosion periods: (a)7d; (b)14d; (c)21d; (d)28d 


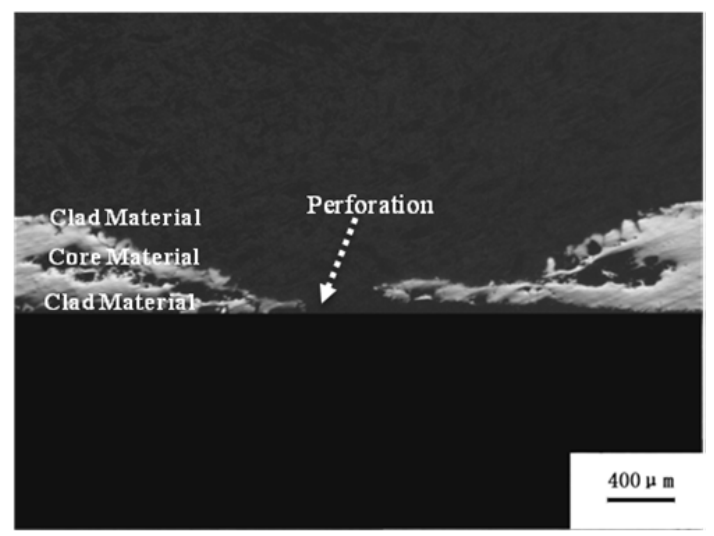

Fig.9 Corrosion morphologies of a normal triple-layer brazed material at the corrosion period of 7 days

The corrosion morphologies of a normal triple-layer brazed material at the corrosion period of 7 days is shown in Fig.9. In contrast to the normal triple-layer brazed material at the same thickness, the time to perforation of the modified four-layer brazing sheet is increased by more than $200 \%$.

\section{Discussion}

The varies corrosion forms of the material during the SWAAT test is the result of the mcriostructure evolution duiring the brazing process. According to the Al-Si binary phase diagram, duiring the barzing process, the primary $\alpha(\mathrm{Al})$ precipitates at the interface of liquid clad and solid core materials prior to the Al-Si eutectic, then Al-Si eutectic accumulates at the surface and in between the primary $\alpha(\mathrm{Al})$ grains at a lower temperature (Fig.2c). Besides, the $\alpha-\mathrm{Al}(\mathrm{Fe}, \mathrm{Mn}) \mathrm{Si}$ phases, which are transformed from $\beta$-AlFeSi due to the diffusion of $\mathrm{Mn}$ element during brazing, is in favor of accumulating at boundaries of the $\alpha(\mathrm{Al})$ and Al-Si eutectic. As it is shown in Fig.1(b), the $30 \sim 40 \mu \mathrm{m}$ width areas with a darker contrast is the so-called BDP, which is the consequence of the diffusion of $\mathrm{Si}$ and elements during brazing[8]. The major phases of BDP has been reported as $\mathrm{Al}_{6}(\mathrm{Fe}, \mathrm{Mn})$ and $\alpha-\mathrm{Al}(\mathrm{Fe}, \mathrm{Mn}) \mathrm{Si}$ phases[11]( Fig.5 and Table 2).

The eutectic (Al) of residual brazing layer has a high sensitivity of pitting in solutions containing Chloride. During the sea water acid accelerated test, the corrosion form of the air side changed from pitting to the form of inter-granular corrosion (IGC) due to the accumulation of the $\alpha-\mathrm{Al}(\mathrm{Fe}, \mathrm{Mn}) \mathrm{Si}$ phases, as shown in Fig.7(a). When corrosion spread to the band of dense precipitates (BDP), as a consequence of the lower corrosion potential of the dense precipitates $\left(\mathrm{Al}_{6}(\mathrm{Mn}, \mathrm{Fe})\right.$ and $\alpha-\mathrm{Al}(\mathrm{Fe}, \mathrm{Mn}) \mathrm{Si}$ phases[17]), the corrosion form is replaced by the partly exfoliation. Therefore, the existence of BDP is beneficial to the prolonging of material's perforation time. The corrosion behavior changed to typical pitting and IGC, while it comes to the core (Fig.5c).

As with the air side, the corrosion of the residual clad began in the typical form of pitting and IGC. When it comes to the 7072 layer, the corrosion form becomes the typical uniform exfoliation. It was found that the 7072 layer that acted as an active cathode to protect not only the core but also the residual clad from corrosion will greatly improves the corrosion life of the material. Finally, the material was failure in the form of IGC and local pitting when corrosion propagated to the core.

\section{Conclusion}

1. The existence of $\operatorname{BDP}($ the band of dense precipitates), which forms at the interface between clad (AA4045) and core (AA3003 $+\mathrm{Cu}$ ) layer during brazing, changes the corrosion form of the air side of the material from inter-granular corrosion to local exfoliation corrosion.

2. The addition of anti-corrosion layer makes the corrosion form of the water side from inter-granular corrosion into uniform exfoliation corrosion.

3. Compared to the normal $\mathrm{O}$ temper triple-layer (AA4045/AA3003/AA4045) brazing sheet at the same thickness, the time to perforation of the modified four-layer brazing sheet is increased by more than $200 \%$. 


\section{Acknowledgments}

Authors would like to thank the support from Jiangsu Key Laboratory for Clad Materials (No:BM2014006), International Science \& Technology Cooperation Program of Wuxi city (No:CZE02H1504), Program on Jiangsu Science and technology achievements transformation (No:BA2015079).

\section{References}

1. Ali Davoodi, Mechanistic studies of localized corrosion of $\mathrm{Al}$ alloys by high resolution in-situ and ex-situ probing techniques, Ph.D Thesis, Royal Institute of Technology, Stockholm, Sweden, 2007: p.1.

2. A.C. Scott, R.A. Woods, J.F. Harris, Accelerated corrosion test methods for evaluating external corrosion resistance of vacuumed brazed aluminum heat exchangers, in: Conference Proceedings of SAE International Congress, SAE, Warrendale, USA, 1991.

3. Y. Isobe, K. Takeuchi, M. Tanaka, M. Mori, S. Yamauchi, K. Namba, Development of corrosion resistant brazing sheet for drawn cup type evaporators part 2:Application to evaporator, in: SAE: Conference Proceedings of SAE International Congress, SAE, Warrendale, USA, 1993.

4. F.M. Al-Kharafi, W.A. Badawy, Corrosion and passivation of al and al-si alloys in nitric acid solutions: 2 - effect of chloride ions, Electrochimica Acta 40 (1995)1811.

5. S.S. Abdel Rehim, H.H. Hassan, M.A. Amin, Chronoamperometric studies of pitting corrosion of $\mathrm{Al}$ and (Al-Si) alloys by halide ions in neutral sulphate solutions, Corrosion Science 46 (2004) 1921.

6. S. Kuroda, K. Tohma, Aluminum alloys, in: Conference Proceedings of ICAA6, Japan Institute of Light Metals, Toyohashi, Japan, 1998, p.1543.

7. S. Meijers, Corrosion of aluminum brazing sheet, Ph.D. Thesis, TU Delft, 2002, ISBN: 90-805661-3-6.

8. S. Tierce, N. Pebere, C. Blanc, C. Casenave, G. Mankowski, H. Robidou, Corrosion behavior of brazing material AA4343, Electrochim. Acta 52
(2006) 1092-1100.

9. Y.J. Li, L. Arnberg, Quantitative study on the precipitation behavior of dispersoids in DC-cast AA3003 alloy during heating and homogenization, Acta Materialia 51(2003): 3415-3428.

10. F. Norouzi Afshar, J.H.W. de Wit, H. Terryn, J.M.C. Mol, Scanning Kelvin probe force microscopy as a means of predicting the electrochemical characteristics of the surface of a modified $\mathrm{AA} 4 \mathrm{xxx} / \mathrm{AA} 3 \mathrm{xxx}(\mathrm{Al}$ alloys $)$ brazing sheet, Electrochimica Acta 88 (2013): 330- 339.

11. S.Tierce, N. Pe'be're, et.al., Corrosion behavior of brazed multilayer material AA4343/AA3003/AA4343: Influence of coolant parameters, Corrosion Science 49(2007) 4581-4593.

12. F. Norouzi Afshar, J.H.W. de Wit, H. Terryn, J.M.C. Mol, The effect of brazing process on microstructure evolution and corrosion performance of a modified AA4XXX/AA3XXX brazing sheet, Corrosion Science, 58 (2012) 242-250.

13. G.J. MARSHALL, et.al. Microstructural Control in an Aluminum Core Alloy for Brazing Sheet Applications, METALLURGICAL TRANSACTIONS A, 24A(1993): 1935-1942.

14. J. Lacaze, S. Tierce, M.C. Lafont, Y. Thebault, N. Pebere, G. Mankowski, C. Blanc, H. Robidou, D. Vaumousse, D. Daloz, Study of the microstructure resulting from brazed aluminum materials used in heat exchangers, Mater. Sci. Eng., A 414 (2005): 317-321.

15. ASTM Standard, Designation G85, Standard Practice for Modified Salt Spray(Fog) Testing, 2006.

16. D.T.L. Alexandre, A.L. Greer, Acta Mater. 50 (2002) :2571.

17. N. Birbilis, R. G. Buchheit, Electrochemical Characteristics of Intermetallic Phases in Aluminum Alloys: An Experimental Survey and Discussion, Journal of The Electrochemical Society, 2005,152 (4): B140-B151. 